\title{
Comportamento dos Custos das Empresas de Construção Civil Listadas na B3 entre 2008 e 2017
}

Amanda Correia de Oliveira
Graduação em Ciências Contábeis pela Universidade Federal de Alagoas - UFAL
Contadora
Av. Lourival Melo Mota. Tabuleiro do Martins. Maceió/AL. CEP: 57.072-900
E-mail: amanda.c.de.oliveira5@gmail.com

Bárbara Vilela David

Graduação em Ciências Contábeis pela Universidade Federal de Alagoas - UFAL

Contadora

Av. Lourival Melo Mota. Tabuleiro do Martins. Maceió/AL. CEP: 57.072-900

E-mail:kla.guedes@hotmail.com

Valdemir da Silva

Mestrado em Ciências Contábeis pela Universidade Federal de Pernambuco - UFPE

Professor Assistente da Universidade Federal de Alagoas - UFAL

Av. Lourival Melo Mota. Tabuleiro do Martins. Maceió/AL. CEP: 57.072-900

E-mail: valdemir.silva@feac.ufal.br

Kleber Luis Alves Guedes

Doutorado em andamento em Ciências Contábeis pela Fucape Business School -

FUCAPE

Professor da Universidade Federal de Alagoas - UFAL Av. Lourival Melo Mota. Tabuleiro do Martins. Maceió/AL. CEP: 57.072-900

E-mail:kla.guedes@hotmail.com

José Jonas Alves Correia

Doutorado em andamento em Ciências Contábeis pela Universidade Federal de

Pernambuco - UFPE

Professor da Universidade Federal de Pernambuco - UFPE

Av. Prof. Moraes Rego, 1235. Cidade Universitária. Recife/PE. CEP: 50.670-901

E-mail: profjonasalves@gmail.com

\section{RESUMO}

As organizações empresariais encontram-se arraigadas em um cenário de mutações rápidas e constantes. Dentre as mudanças que mais impactam as empresas, pode-se mencionar o acirramento da competitividade, carecido da expansão do nível nacional para o internacional. Assim, a análise de custos preceitua como ferramenta relevante para o gerenciamento das organizações, quando utilizada de forma coerente no processo produtivo ou no controle empresarial, de forma que, permite verificar o comportamento econômico da entidade, além de auxiliar na tomada de decisão. $\mathrm{O}$ 
Comportamento dos Custos das Empresas de Construção Civil Listadas na B3 entre 2008 e 2017

Amanda Correia de Oliveira, Bárbara Vilela David, Valdemir da Silva, Kleber Luis Alves Guedes, José

Jonas Alves Correia

objetivo deste estudo é verificar como se comportam os custos das empresas do ramo da construção civil, listadas na Brasil, Bolsa \& Balcão (B3) entre 2008 e 2017. Para tal, foram coletados dados das demonstrações contábeis referentes ao período analisado. Utilizando-se de uma pesquisa descritiva, levantamento de dados e abordagem quantitativa, verificou-se que as entidades analisadas possuem uma estrutura de custos similar, visto que, nos 10 anos investigados, em média, 76\% da Receita Líquida de Vendas (RLV) dessas empresas foram destinados a cobrir o custo dos produtos vendidos (CPV). Analisando-se a média dos insumos (custos e despesas) em relação à RLV, observou-se que existe uma grande ligação entre eles, pois, à medida que a receita líquida de vendas varia, os custos e despesas se alteram no mesmo sentido. Por fim, observou-se também que os melhores resultados foram apresentados entre os anos de 2008 e 2013 e que, entre os anos de 2014 e 2017, os resultados do ramo da construção civil declinaram.

Palavras-chave: Análise de Custos. Construção Civil. B3.

\section{Behavior of Costs of Civil Construction Companies Listed on the B3 between 2008 and 2017}

\section{ABSTRACT}

Business organizations are rooted in a scenario of rapid and constant change. Among the changes that most impact companies, we can mention the increased competitiveness, lacking the expansion from national to international level. Thus, cost analysis is a relevant tool for the management of organizations, when used consistently in the production process or business control, so that it allows to verify the economic behavior of the entity, as well as assisting in decision making. The purpose of this study is to verify how the costs of construction companies listed in Brazil, Bolsa \& Balcão (B3) between 2008 and 2017 behave. To this end, data were collected from the financial statements for the period analyzed. Using a descriptive research, data collection and quantitative approach, it was found that the entities analyzed have a similar cost structure, since, in the 10 years investigated, on average, $76 \%$ of Net Sales Revenue (NLR) of these companies were intended to cover the cost of goods sold (COGS). Analyzing the average of inputs (costs and expenses) in relation to RLV, it was observed that there is a great connection between them, since, as net sales revenue varies, costs and expenses change in the same direction. Finally, it was also observed that the best results were presented between 2008 and 2013 and that between 2014 and 2017 , the results of the construction industry declined.

Keywords: Cost Analysis. Construction. B3. 
Comportamento dos Custos das Empresas de Construção Civil Listadas na B3 entre 2008 e 2017

Amanda Correia de Oliveira, Bárbara Vilela David, Valdemir da Silva, Kleber Luis Alves Guedes, José

Jonas Alves Correia

\section{INTRODUÇÃO}

A indústria da construção civil é um dos mais representativos setores econômicos do Brasil. Isso se deve ao fato de que ainda existe um grande déficit habitacional no país; no entanto, vale reforçar que o segmento alcança toda e qualquer atividade relacionada à produção de obras (Oliveira, 2012).

De acordo com Souza, Oliveira, Santana, Viana Neto e Santos (2015), tradicionalmente, o desenvolvimento desse setor econômico acompanha o que acontece na economia brasileira. Assim sendo, se a economia vai bem, o setor apresenta alta demanda e, consequentemente, oportunidades de emprego, porém, quando há crise na economia, o setor também é atingido diretamente.

Conforme os dados divulgados pela Câmara Brasileira da Indústria da Construção - CBIC (2018), entre 2014 e 2017 a indústria da construção vem amargurando desempenho negativo. Nessa perspectiva, Gonçalves (2015) afirma que, diante dos reflexos da instabilidade econômica na construção civil, as empresas precisam adequar-se a essa realidade, sendo a contenção de custos uma das principais estratégias para assegurar bons resultados nesses períodos de incerteza econômica. Porém, essa estratégia precisa ser bem elaborada e programada.

Neste panorama, Cabral (2015) compreende que a gestão de custos é uma das estratégias de as empresas minimizarem os gastos desnecessários, oferecendo aos gestores a compreensão da dinâmica dos resultados da empresa (Medeiros, Costa, \& Silva, 2005). Desse modo, a investigação do comportamento dos custos é basilar para o controle gerencial, maximização dos lucros e crescimento do nível de competitividade (Oliveira, Lustosa, \& Sales, 2007).

Fontenele Filho e Correia Neto (2014) afirmam que a gestão de custos é uma atividade essencial em projetos de todos os portes, já que o planejamento ou o controle dos custos, quando geridos de forma incorreta, podem prejudicar o sucesso de um projeto e influenciar diretamente outras áreas de gestão como escopo e tempo. 
Comportamento dos Custos das Empresas de Construção Civil Listadas na B3 entre 2008 e 2017

Amanda Correia de Oliveira, Bárbara Vilela David, Valdemir da Silva, Kleber Luis Alves Guedes, José

Jonas Alves Correia

Para Bornia (2005), os gestores e investidores têm a necessidade de obter esclarecimentos acerca dos custos de suas empresas, com o intuito de alcançar melhorias e sobreviver nos períodos de crise.

Considerando o contexto apresentado, emerge a seguinte pergunta de pesquisa: Como se comportam os custos das empresas de construção civil listadas na B3 entre 2008 e 2017? Sendo assim, o objeto desta pesquisa é verificar o comportamento dos custos no setor de construção civil entre os anos de 2008 e 2017 das empresas listadas na B3.

Sabe-se que a Contabilidade de custos possui relevante papel na gestão de uma empresa. Tratando-se do ramo da construção civil, ela é essencial, pois permite a formação de índices que levam à avaliação do lucro de cada obra e, consequentemente, do resultado da empresa (Azienda, 2017).

Dessa forma, a busca pela compreensão do comportamento dos custos na construção civil se justifica tanto pela sua relevância para pesquisadores e acadêmicos, quanto para os usuários internos e externos, já que entender o impacto dos custos na atividade empresarial permite a avaliação do desempenho econômico-financeiro da entidade e a tomada de decisão por parte de gestores e investidores.

Em termos estruturais, o estudo está organizado em cinco seções. Após esta, de caráter introdutório, segue a segunda seção que aborda o cenário da construção civil, o comportamento dos custos e estudos correlatos ao tema abordado. Na terceira seção, são apresentados os aspectos metodológicos da pesquisa, cujos resultados são apontados na quarta seção. Por fim, a quinta e última seção trazem as considerações finais da pesquisa, bem como apontamento de sugestões para novas investigações.

\section{REFERENCIAL TEÓRICO}

\subsection{Cenário da construção civil no Brasil}

A construção civil surgiu no Brasil durante a sua colonização, mas, de acordo com Duarte (2013), este setor começou a viver seu auge durante o governo de Getúlio 
Comportamento dos Custos das Empresas de Construção Civil Listadas na B3 entre 2008 e 2017

Amanda Correia de Oliveira, Bárbara Vilela David, Valdemir da Silva, Kleber Luis Alves Guedes, José

Jonas Alves Correia

Vargas (meados de 1940), por meio da habitação popular e do forte investimento estatal no desenvolvimento de estrutura para construção civil e militar. A partir daí, a iniciativa privada também entrou no setor, fazendo com que este se modernizasse e buscasse maior qualidade no produto final.

Segundo Martins Júnior (2016), o setor se divide em três áreas de atuação: mercado imobiliário, setor público e prestação de serviços. O primeiro está voltado para a construção e venda de imóveis residenciais ou comerciais. O segundo compreende as construções pesadas de viadutos, aeroportos, estradas e outras obras, cujo cliente é o poder público. E o último são prestações de serviços de construções que incluem desde as pequenas reformas até grandes serviços em shoppings ou multinacionais.

Em seu aspecto econômico, a construção civil viveu momentos de grande incentivo advindos do governo federal. Em 2007, com o Programa de Aceleração do Crescimento (PAC), por meio do Decreto $\mathrm{n}^{\circ}$ 6.025/2007, e em 2009, mediante a instituição do programa social Minha Casa, Minha Vida, da Lei ํㅜ⒒977/2009, esses programas aqueceram o setor e impulsionaram a alavancagem desse mercado.

Porém, a partir de 2014, o setor foi atingido pela crise econômica e política vivida no país. Conforme o Sinicon (2017), o setor foi o que apresentou maior queda, amargando um encolhimento de $21 \%$ do segundo trimestre de 2014 até o segundo trimestre de 2017. Ainda, conforme o mesmo, o desempenho é considerado como digno de uma depressão econômica, sendo apontadas como causas: o colapso nas contas do governo, que derrubaram as obras públicas, e os escândalos de corrupção que atingiram as grandes empreiteiras.

Apesar da queda no segmento, um reflexo da recuperação e da credibilidade da economia do país já pode ser vista com o crescimento do mercado de trabalho no primeiro trimestre de 2018. Esse crescimento foi acompanhado pelo setor de construção que apresentou saldo positivo de 7,8 mil novos empregos, dos quais 3,5 mil foram na construção pesada (infraestrutura e montagem) e 4,3 mil na construção civil (edificações e instalações) (Sinicon, 2018). 
Comportamento dos Custos das Empresas de Construção Civil Listadas na B3 entre 2008 e 2017

Amanda Correia de Oliveira, Bárbara Vilela David, Valdemir da Silva, Kleber Luis Alves Guedes, José

Jonas Alves Correia

\subsection{Comportamento dos custos}

Em reação à competividade advinda da globalização e modernização dos negócios, em âmbito mundial e nacional, as empresas são conduzidas a um monitoramento de forma mais detalhada e precisa dos custos (Richatz, Borgert, Vicente, \& Ferrari, 2012), isso porque, no atual ambiente empresarial, as organizações necessitam reduzir os custos, ao mesmo tempo que aumentam a qualidade dos produtos e/ou serviços disponibilizados (Gomes, Lima, \& Steppan, 2007a).

Assim, utilizar os custos na gestão estratégica da organização permite aos administradores o conhecimento de informações relevantes, porquanto envolve o quanto, quando e em que setor deverá ser investido ou sobre quanto devem custar os produtos/serviços que a organização produz (Martins, 2009). Por isso, o conhecimento dos custos deve ser utilizado como um medidor do desempenho econômico-financeiro para promoção da tomada de decisão (Maher, 2001; Lima, Egito, \& Silva, 2004).

Nesse sentido, os gestores que compreendem o comportamento dos custos têm maiores chances de prever qual a trajetória dos custos em diversas circunstâncias operacionais e, assim, esquematizar melhor suas atividades e, em decorrência disso, gerar mais lucro (Medeiros et al., 2005). Sob o mesmo ponto de vista, Garrison, Norren e Brewer (2013) afirmam que gestor que analisar o modo pelo qual os custos se comportam em função das alterações do nível de atividade será capaz de predizer como os custos variam sob diversas alternativas.

Para Shank e Govindarajan (1997), a compreensão do comportamento do custo se dá pelo entendimento da complexa interação do conjunto de direcionadores de custos em ação de uma determinada situação. Gomes, Lima e Steppan (2007b) descrevem que o comportamento dos custos minimiza, para os gestores, as dúvidas de como os custos são gerados quando as atividades são desempenhadas.

Em razão do exposto, compreender o comportamento dos custos significa depreender a forma pela qual esses gastos operacionais se alteram em função de variações nos níveis de atividades e da estrutura operacional da empresa ao considerar as influências ambientais e econômicas (Richartz, Borgert, Vicente \& Ferrari, 2012). 
Comportamento dos Custos das Empresas de Construção Civil Listadas na B3 entre 2008 e 2017

Amanda Correia de Oliveira, Bárbara Vilela David, Valdemir da Silva, Kleber Luis Alves Guedes, José

Jonas Alves Correia

A busca pela compreensão do comportamento dos custos nas organizações não é uma tarefa tão simples de ser realizada. Diante desse desafio, diversas pesquisas (Richartz et al., 2012; Ferrari, Kremer, \& Pinheiro, 2013; Rigo, Godoy, \& Scarpin, 2016; Macedo, Sancovschi, Leira, \& Silva, 2016; Engelage, Vargas, Reis, \& Borgert, 2017; Fazoli, Reis, \& Borgert, 2018) já foram realizadas com o objetivo de investigar custos empresariais, inclusive nas entidades listadas na B3, porém os resultados mostram que, diante das dificuldades encontradas para a sua compreensão, não existe um consenso para explicar o comportamento dos custos empresariais.

\subsection{Estudos correlatos}

Richartz et al. (2012) utilizaram análise e correlações estatísticas em uma amostra de 14 empresas, objetivando identificar o comportamento dos custos das empresas brasileiras do segmento de fios e tecidos listadas na B3 entre 1998 e 2010. Os resultados da pesquisa revelaram que $78 \%$ da receita é comprometida pelo CPV, $15 \%$ pelas despesas administrativas e $10 \%$ pelas despesas de vendas. A investigação também mostrou que o grau de alavancagem operacional das empresas com receita mais elevada é maior que o das empresas com baixo faturamento, e que as empresas que apresentam melhor relação CPV/RLV são aquelas que apresentam menor Receita. Além disso, o estudo confirma a teoria dos Sticky Costs para as variações de receitas de 0 a $15 \%$ e de 15 a $30 \%$, uma vez que os custos apresentaram comportamento assimétrico. Todavia, a referida teoria não foi confirmada para as variações da receita acima de $30 \%$.

Já Ferrari et al. (2013) estudaram o comportamento dos custos em função das mudanças regulatórias nas empresas do segmento de telecomunicações listadas na B3. A pesquisa contemplou 10 empresas (8 Telefonias fixas e 2 telefonias móveis) em um período de 18 anos (1995 a 2012). De maneira individual, constatou-se que as despesas de vendas e o CPV apresentaram maior variação nos períodos em que houve uma maior promulgação de leis, permitindo a entrada de novas empresas no setor, e que apenas as despesas financeiras e de vendas apresentaram tendência de 
Comportamento dos Custos das Empresas de Construção Civil Listadas na B3 entre 2008 e 2017

Amanda Correia de Oliveira, Bárbara Vilela David, Valdemir da Silva, Kleber Luis Alves Guedes, José

Jonas Alves Correia

crescimento moderada e fraca, respectivamente. Como resultado geral, verificou-se que os custos das empresas são afetados pela regulamentação do setor, visto que, até 2003 (quando a legislação permitiu a entrada de novas empresas no setor), os custos totais apresentaram maior oscilação e que, após esse período, ocorreu uma estabilidade dessa relação.

Rigo et al. (2016) buscaram identificar o comportamento dos custos dos produtos fabricados das empresas do setor de alimentos processados, segmento de carnes e derivados listados na BM\&FBOVESA no período de 2007 a 2011. Investigando uma amostra de 6 empresas, o estudo verificou que a evolução dos custos e despesas operacionais em relação às receitas correspondia a uma média de $81,19 \%$ dos CPV sobre a receita liquida. Utilizando regressão estatística para identificar os custos fixos e variáveis, a pesquisa encontrou um aumento de $64,21 \%$ no grau de alavancagem operacional das empresas, levando à evidência de que o segmento elevou o risco das operações supostamente por meio do aumento da representatividade dos custos fixos perante as receitas auferidas.

Ainda no que compete ao estudo dos custos, Macedo et al. (2016) analisaram o comportamento dos custos das operadoras de saúde reguladas pela Agência Nacional de Saúde Suplementar (ANS) entre 2001 e 2015 por meio de uma perspectiva de Sticky Costs. Nessa pesquisa, foram coletados os dados econômico-financeiros, disponibilizados no site da ANS, os quais compuseram a amostra de 1.995 operadorasano. Tal estudo, utilizando a análise de regressão pooled, apontou a existência de custos assimétricos para os elementos de custos: eventos indenizáveis líquidos, despesas administrativas e despesas de comercialização.

Engelage et al. (2017) investigaram como o comportamento dos custos das empresas listadas na B3 são afetados pelos períodos de instabilidade econômica. Para isso, utilizou o método de regressão para dados em painel a fim de verificar se a relação CPV/RLV é impactada pelo Índice de Atividade Econômica do Banco Central (IBC- $\mathrm{Br}$ ) e pelo valor das ações. Os resultados revelaram que o aumento de indicadores da economia nacional e da valorização de mercado das empresas reflete 
Comportamento dos Custos das Empresas de Construção Civil Listadas na B3 entre 2008 e 2017

Amanda Correia de Oliveira, Bárbara Vilela David, Valdemir da Silva, Kleber Luis Alves Guedes, José

Jonas Alves Correia

maior eficiência no comportamento dos custos. Da mesma forma, em períodos de instabilidade econômica, quando os indicadores tendem a sofrer queda, a eficiência de custos também diminui. Já os resultados setorizados indicaram que apenas os setores de Telecomunicações, de Energia Elétrica e de Veículos e Peças apresentam variáveis que mensuram instabilidade econômica.

De forma semelhante, Fazoli et al. (2018) estudaram o comportamento dos custos do setor industrial do estado de Santa Catarina, com ênfase nos Sticky Costs, sob duas óticas: a indústria como um todo e por segmento. Os resultados mostraram que, de maneira geral, houve um aumento de $0,7781 \%$ de custos a cada $1 \%$ de incremento na receita; por outro lado, quando a receita de vendas se reduz em 1 (redução marginal), há uma redução de 0,7632\% nos custos. Ademais, da análise individualizada por setor, constatou-se que, além do comportamento Sticky em conformidade com a média, alguns segmentos apresentaram comportamento assimétrico dos custos, enquanto outros apresentaram comportamento anti-sticky.

Em virtude da complexidade apresentada e da necessidade no âmbito do conhecimento científico, além do amplo campo a ser explorado em termos investigativos, esta pesquisa tem por intuito contribuir, no que tange ao desenvolvimento da temática abordada, para o entendimento do comportamento dos custos, em específico, no segmento da construção civil nos exercícios de 2008 a 2017.

\section{ASPECTOS METOdOLÓGICOS}

No que se refere ao enquadramento metodológico, esta pesquisa, quanto ao seu objetivo, é classificada em descritiva, pois visa demonstrar as características de comportamento do custo das empresas do setor de construção civil listadas na B3, buscando descrever, relatar e interpretar a realidade observada e estabelecer correlações entre variáveis (Beüren, 2008).

Para alcançar tal objetivo, o procedimento técnico utilizado é o levantamento, uma vez que, examinando as demonstrações contábeis anuais das empresas 
investigadas no período de 2008 a 2017, foram coletados dados secundários que ainda não tinham recebido tratamento analítico. A abordagem adotada é predominantemente quantitativa, pois foram utilizados recursos estatísticos para a análise e tratamento dos dados coletados (Richardson, 2017).

Para a realização deste estudo, foram selecionadas as empresas de construção civil listadas no segmento de edificações da B3, na qual estão listadas 19 empresas. A análise compreende as demonstrações contábeis apresentadas entre 2008 e 2017. Conforme Richartz et al. (2012), este corte temporal de 10 anos contribui para que ocorra o equilíbrio entre a dimensão temporal e os elementos que compõem a amostra, pois, quando se investiga o comportamento dos custos, as análises amparadas em séries temporais maiores poderão fornecer maior credibilidade aos resultados encontrados, além de evidenciarem melhor as tendências de custos individuais e do segmento.

Em relação às entidades listadas no segmento de edificações da $B 3$, cabe ressaltar que a empresa mineira Inter Construtora e Incorporadora S.A. apresenta dados apenas a partir de 2016 e, por isso, não faz parte da amostra, limitando-se a 18 empresas, conforme Figura 1. 
Comportamento dos Custos das Empresas de Construção Civil Listadas na B3 entre 2008 e 2017

Amanda Correia de Oliveira, Bárbara Vilela David, Valdemir da Silva, Kleber Luis Alves Guedes, José

Jonas Alves Correia

\begin{tabular}{|c|c|c|c|c|}
\hline & Razão Social & $\begin{array}{l}\text { Nome do } \\
\text { Pregão }\end{array}$ & UF & $\begin{array}{c}\text { Período com } \\
\text { demonstrações }\end{array}$ \\
\hline 1 & CONSTRUTORA ADOLPHO LINDENBERG S.A. & CONST. A LIND & SP & $1997-2018$ \\
\hline 2 & CONSTRUTORA TENDA S.A. & TENDA & SP & $2006-2018$ \\
\hline 3 & CR2 EMPREENDIMENTOS IMOBILIARIOS S.A. & CR2 & RJ & $2006-2018$ \\
\hline 4 & $\begin{array}{l}\text { CYRELA BRAZIL REALTY S.A. EMPREEND. E } \\
\text { PART. }\end{array}$ & CYRELA REALT. & SP & $1997-2018$ \\
\hline 5 & DIRECIONAL ENGENHARIA S.A. & DIRECIONAL & MG & $2006-2018$ \\
\hline 6 & EVEN CONSTRUTORA E INCORPORADORA S.A. & EVEN & SP & $2005-2018$ \\
\hline 7 & EZ TEC EMPREEND. E PARTICIPACOES S.A. & EZTEC & SP & $2006-2018$ \\
\hline 8 & GAFISA S.A. & GAFISA & SP & $1997-2018$ \\
\hline 9 & HELBOR EMPREENDIMENTOS S.A. & HELBOR & SP & $2006-2018$ \\
\hline 10 & JHSF PARTICIPACOES S.A. & JHSF PART. & SP & $2006-2018$ \\
\hline 11 & JOAO FORTES ENGENHARIA S.A. & JOAO FORTES & RJ & $1997-2018$ \\
\hline 12 & MRV ENGENHARIA E PARTICIPACOES S.A. & MRV & MG & $2006-2018$ \\
\hline 13 & $\begin{array}{l}\text { PDG REALTY S.A. EMPREEND. E } \\
\text { PARTICIPAÇÕES }\end{array}$ & PDG REALT. & SP & $2005-2018$ \\
\hline 14 & RNI NEGÓCIOS IMOBILIÁRIOS S.A. & RNI & SP & $2005-2018$ \\
\hline 15 & ROSSI RESIDENCIAL S.A. & ROSSI RESID. & SP & $2000-2018$ \\
\hline 16 & TECNISA S.A. & TECNISA & SP & $2006-2018$ \\
\hline 17 & TRISUL S.A. & TRISUL & SP & $2007-2018$ \\
\hline 18 & VIVER INCORPORADORA E CONSTRUTORA S.A. & VIVER & SP & $2006-2018$ \\
\hline
\end{tabular}

Figura 1. Empresas pertencentes à amostra

Fonte: B3 (2018).

A base de dados desta pesquisa é composta pela Receita Líquida $(R L)$, Custo dos Produtos Vendidos (CPV), Despesas de vendas (DV) e Despesas Administrativas (DA). Com o propósito de viabilizar a execução da pesquisa, os dados são registrados para planilhas do software Microsoft Exceß. Para minimizar as influências temporais sobre os valores dos dados coletados, estes foram ajustados, para dezembro de 2017, pelo índice de inflação do IPCA.

Feito isso, foi realizada, no próprio Excel, uma estatística descritiva para efetuar os seguintes cálculos: (i) variação da receita líquida e dos custos dos produtos vendidos (CPV) durante os anos investigados; (ii) relação entre o CPV e a receita líquida; (iii) relação entre as despesas de venda e a receita líquida; (iv) relação entre as despesas administrativas e a receita líquida; (v) Média dos custos e despesas em relação à receita líquida. Com isso, atende-se ao objetivo estabelecido na pesquisa. 


\section{APRESENTAÇÃO E ANÁLISE DOS DADOS}

A fim de evidenciar os achados da pesquisa, a apresentação dos dados será realizada em dois subitens, sendo abordados no primeiro os aspectos relacionados à variação das receitas e dos custos, relacionando as variações entre si. No segundo, serão expostas a média e os coeficientes de variação dos custos e despesas relacionados à receita líquida de venda.

\subsection{Análise das variações das receitas e dos custos}

Por meio dos dados coletados, foi possível realizar a análise das variações da receita líquida e dos custos dos produtos vendidos durante os 10 anos, para detectar se eles aumentam, diminuem ou se estabilizam no período. A Tabela 1 apresenta a variação de um ano para o outro da receita de cada empresa. 
Comportamento dos Custos das Empresas de Construção Civil Listadas na B3 entre 2008 e 2017

Amanda Correia de Oliveira, Bárbara Vilela David, Valdemir da Silva, Kleber Luis Alves Guedes, José Jonas Alves Correia

Tabela 1

Variação das receitas líquidas (RL) no período de 2008 a 2017

\begin{tabular}{|c|c|c|c|c|c|c|c|c|c|c|}
\hline Empresa & \&̊ & 오 & 웅 & స్ & № & $\sum_{\text {N }}^{m}$ & ণ্ণ & ำ & $\frac{0}{\sim}$ & స్ \\
\hline CONST A LIND & $-46 \%$ & $-6 \%$ & $-15 \%$ & $95 \%$ & $63 \%$ & $25 \%$ & $-1 \%$ & $-5 \%$ & $-46 \%$ & $-58 \%$ \\
\hline TENDA & $92 \%$ & $88 \%$ & $0 \%$ & $-61 \%$ & $137 \%$ & $-31 \%$ & $-34 \%$ & $40 \%$ & $12 \%$ & $21 \%$ \\
\hline CR2 & $353 \%$ & $20 \%$ & $35 \%$ & $-58 \%$ & $-24 \%$ & $-34 \%$ & $-83 \%$ & $40 \%$ & $-48 \%$ & $-37 \%$ \\
\hline CYRELA REALT & $35 \%$ & $33 \%$ & $12 \%$ & $16 \%$ & $-11 \%$ & $-13 \%$ & $2 \%$ & $-30 \%$ & $-33 \%$ & $-21 \%$ \\
\hline DIRECIONAL & $143 \%$ & $32 \%$ & $93 \%$ & $27 \%$ & $20 \%$ & $20 \%$ & $-1 \%$ & $-20 \%$ & $-22 \%$ & $-48 \%$ \\
\hline EVEN & $86 \%$ & $30 \%$ & $56 \%$ & $-10 \%$ & $6 \%$ & $7 \%$ & $-15 \%$ & $-6 \%$ & $-29 \%$ & $-15 \%$ \\
\hline AZTEC & $69 \%$ & $40 \%$ & $17 \%$ & $8 \%$ & $1 \%$ & $35 \%$ & $-21 \%$ & $-20 \%$ & $-37 \%$ & $61 \%$ \\
\hline GAFISA & $37 \%$ & $60 \%$ & $5 \%$ & $-20 \%$ & $26 \%$ & $-41 \%$ & $-40 \%$ & $-14 \%$ & $-43 \%$ & $-37 \%$ \\
\hline HELBOR & $26 \%$ & $75 \%$ & $41 \%$ & $10 \%$ & $14 \%$ & $13 \%$ & $-12 \%$ & $-23 \%$ & $-38 \%$ & $-46 \%$ \\
\hline JHSF PART & $111 \%$ & $-32 \%$ & $43 \%$ & $10 \%$ & $-7 \%$ & $-29 \%$ & $-17 \%$ & $1 \%$ & $-45 \%$ & $-13 \%$ \\
\hline JOAO FORTES & $16 \%$ & $132 \%$ & $94 \%$ & $-1 \%$ & $-15 \%$ & $58 \%$ & $-22 \%$ & $-34 \%$ & $-62 \%$ & $-34 \%$ \\
\hline MRV & $163 \%$ & $37 \%$ & $71 \%$ & $23 \%$ & $0 \%$ & $-14 \%$ & $2 \%$ & $7 \%$ & $-19 \%$ & $5 \%$ \\
\hline PDG REALT & $111 \%$ & $49 \%$ & $146 \%$ & $22 \%$ & $-40 \%$ & $15 \%$ & $-24 \%$ & $-60 \%$ & $-88 \%$ & $74 \%$ \\
\hline RNI & $205 \%$ & $7 \%$ & $41 \%$ & $-2 \%$ & $0 \%$ & $-11 \%$ & $-10 \%$ & $-27 \%$ & $-37 \%$ & $-29 \%$ \\
\hline ROSSI RESID & $54 \%$ & $18 \%$ & $39 \%$ & $12 \%$ & $-10 \%$ & $-26 \%$ & $-28 \%$ & $-29 \%$ & $-60 \%$ & $-43 \%$ \\
\hline TECNISA & $38 \%$ & $33 \%$ & $79 \%$ & $5 \%$ & $-19 \%$ & $27 \%$ & $-15 \%$ & $-26 \%$ & $-76 \%$ & $-15 \%$ \\
\hline TRISUL & $67 \%$ & $64 \%$ & $31 \%$ & $-8 \%$ & $-25 \%$ & $-22 \%$ & $-33 \%$ & $-4 \%$ & $-28 \%$ & $37 \%$ \\
\hline VIVER & $185 \%$ & $-20 \%$ & $49 \%$ & $-19 \%$ & $-54 \%$ & $47 \%$ & $-71 \%$ & $-34 \%$ & $-114 \%$ & $-131 \%$ \\
\hline
\end{tabular}

Nota. Fonte: dados da pesquisa, 2018.

Verifica-se, pela Tabela 1, que a maior parte das empresas apresentaram crescimento na sua receita entre 2008 e 2010, com exceção das empresas Const. A Lind., que reduziu a sua receita nos três anos, Jhsf e Viver, que declinaram apenas em 2009. Já no período de 2011 a 2013, a situação se inverteu, pois a maioria obteve redução de receita em 1,2 ou 3 anos. Apenas Const. A Lind., Direcional, Azetc e Helbor aumentaram a sua receita.

$\mathrm{Na}$ análise de 2014 a 2017, nota-se que novamente as empresas apresentaram redução, mas, nesse período, todas diminuíram a sua receita em pelo menos um dos anos. Foi o pior desempenho da empresa Viver que teve queda nos 4 anos, e o melhor da Tenda, que reduziu sua receita apenas em 2014, voltando a crescer nos anos seguintes. Vale ressaltar que o país viveu uma crise política e econômica entre 2014 e 
Comportamento dos Custos das Empresas de Construção Civil Listadas na B3 entre 2008 e 2017

Amanda Correia de Oliveira, Bárbara Vilela David, Valdemir da Silva, Kleber Luis Alves Guedes, José Jonas Alves Correia

2016 e o fato de o desenvolvimento das atividades de construção civil terem sido sensíveis às variações na economia pode ser uma das causas que levaram as empresas a apresentarem tal desempenho.

De modo geral, na análise dos 10 anos, as receitas de vendas, na maioria das empresas, mantiveram-se estáveis entre os anos de 2008 e 2013, apresentando algumas reduções pontuais nesse período, porém, entre 2014 e 2017, predominam as variações negativas.

A Tabela 2 evidencia as variações percentuais dos Custos dos Produtos Vendidos (CPV) no período analisado.

Tabela 2

Variação dos custos (CPV) no período de 2008 a 2017

\begin{tabular}{|c|c|c|c|c|c|c|c|c|c|c|}
\hline Empresa & 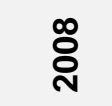 & 옹 & 웅 & Г্ণ & $\stackrel{\sim}{\text { N }}$ & ঙ্ণ & ষ্ণ & $\stackrel{10}{\text { న్ }}$ & $\stackrel{\circ}{\circ}$ & స్⿱ \\
\hline CONST A LIND & $-55 \%$ & $-16 \%$ & $-21 \%$ & $163 \%$ & $41 \%$ & $30 \%$ & $-2 \%$ & $-7 \%$ & $-36 \%$ & $-42 \%$ \\
\hline TENDA & $98 \%$ & $95 \%$ & $2 \%$ & $-8 \%$ & $27 \%$ & $-21 \%$ & $-49 \%$ & $28 \%$ & $9 \%$ & $15 \%$ \\
\hline CR2 & $343 \%$ & $30 \%$ & $29 \%$ & $-66 \%$ & $-3 \%$ & $-41 \%$ & $-87 \%$ & $80 \%$ & $-45 \%$ & $-37 \%$ \\
\hline CYRELA REALT & $36 \%$ & $40 \%$ & $17 \%$ & $21 \%$ & $-14 \%$ & $27 \%$ & $-31 \%$ & $-32 \%$ & $-32 \%$ & $-14 \%$ \\
\hline DIRECIONAL & $124 \%$ & $48 \%$ & $99 \%$ & $34 \%$ & $21 \%$ & $27 \%$ & $-1 \%$ & $-17 \%$ & $-12 \%$ & $-44 \%$ \\
\hline EVEN & $93 \%$ & $40 \%$ & $59 \%$ & $-10 \%$ & $5 \%$ & $8 \%$ & $-15 \%$ & $-1 \%$ & $-25 \%$ & $-9 \%$ \\
\hline AZTEC & $82 \%$ & $60 \%$ & $5 \%$ & $1 \%$ & $-2 \%$ & $33 \%$ & $-21 \%$ & $-17 \%$ & $-31 \%$ & $70 \%$ \\
\hline GAFISA & $32 \%$ & $63 \%$ & $7 \%$ & $1 \%$ & $3 \%$ & $-40 \%$ & $-41 \%$ & $-14 \%$ & $-12 \%$ & $-25 \%$ \\
\hline HELBOR & $18 \%$ & $84 \%$ & $35 \%$ & $13 \%$ & $10 \%$ & $27 \%$ & $-21 \%$ & $-13 \%$ & $-28 \%$ & $-36 \%$ \\
\hline JHSF PART & $126 \%$ & $-12 \%$ & $29 \%$ & $4 \%$ & $-16 \%$ & $-27 \%$ & $-21 \%$ & $13 \%$ & $-42 \%$ & $-15 \%$ \\
\hline JOAO FORTES & $11 \%$ & $167 \%$ & $68 \%$ & $5 \%$ & $1 \%$ & $51 \%$ & $-13 \%$ & $-25 \%$ & $-50 \%$ & $-32 \%$ \\
\hline MRV & $157 \%$ & $43 \%$ & $78 \%$ & $25 \%$ & $4 \%$ & $-12 \%$ & $-1 \%$ & $4 \%$ & $-22 \%$ & $3 \%$ \\
\hline PDG REALT & $112 \%$ & $63 \%$ & $146 \%$ & $27 \%$ & $-5 \%$ & $-23 \%$ & $-23 \%$ & $-49 \%$ & $-53 \%$ & $-58 \%$ \\
\hline RNI & $196 \%$ & $22 \%$ & $31 \%$ & $11 \%$ & $-10 \%$ & $-13 \%$ & $-7 \%$ & $-27 \%$ & $-20 \%$ & $-25 \%$ \\
\hline ROSSI RESID & $53 \%$ & $23 \%$ & $47 \%$ & $16 \%$ & $-6 \%$ & $-24 \%$ & $-23 \%$ & $-28 \%$ & $-58 \%$ & $-26 \%$ \\
\hline TECNISA & $45 \%$ & $33 \%$ & $92 \%$ & $13 \%$ & $-7 \%$ & $6 \%$ & $-16 \%$ & $-23 \%$ & $-60 \%$ & $-6 \%$ \\
\hline TRISUL & $89 \%$ & $72 \%$ & $40 \%$ & $4 \%$ & $-32 \%$ & $-25 \%$ & $-40 \%$ & $4 \%$ & $-28 \%$ & $38 \%$ \\
\hline VIVER & $261 \%$ & $-22 \%$ & $40 \%$ & $-2 \%$ & $-15 \%$ & $1 \%$ & $-61 \%$ & $-33 \%$ & $-69 \%$ & $-76 \%$ \\
\hline
\end{tabular}

Nota. Fonte: dados da pesquisa, 2018. 
Comportamento dos Custos das Empresas de Construção Civil Listadas na B3 entre 2008 e 2017

Amanda Correia de Oliveira, Bárbara Vilela David, Valdemir da Silva, Kleber Luis Alves Guedes, José Jonas Alves Correia

Nos anos de 2008 a 2010, grande parte das empresas aumentou seus custos, exceto a Const. A Lind, que reduziu os custos nos três anos, e a JHSF e Viver, que diminuíram em 2009. No período de 2011 a 2013, a maioria apresentou uma diminuição dos custos em pelo menos um dos anos, com exceção de Const. A Lind, Direcional, Helbor e João Fortes, que aumentaram seus custos. Em relação aos anos de 2014 a 2017, verifica-se que $2 / 3$ das empresas investigadas sofreram reduções sucessivas em seus custos nos quatro anos; as demais apresentaram este mesmo comportamento em pelo menos um dos anos analisados.

Assim como ocorreu com a variação da receita, os custos da maior parte das empresas aumentaram entre 2008 e 2013, com algumas reduções pontuais, principalmente no período de 2012 e 2013, que se estendem para os anos seguintes.

Para melhor visualização da variação geral da receita líquida, a Figura 2 apresenta a variação média por ano.

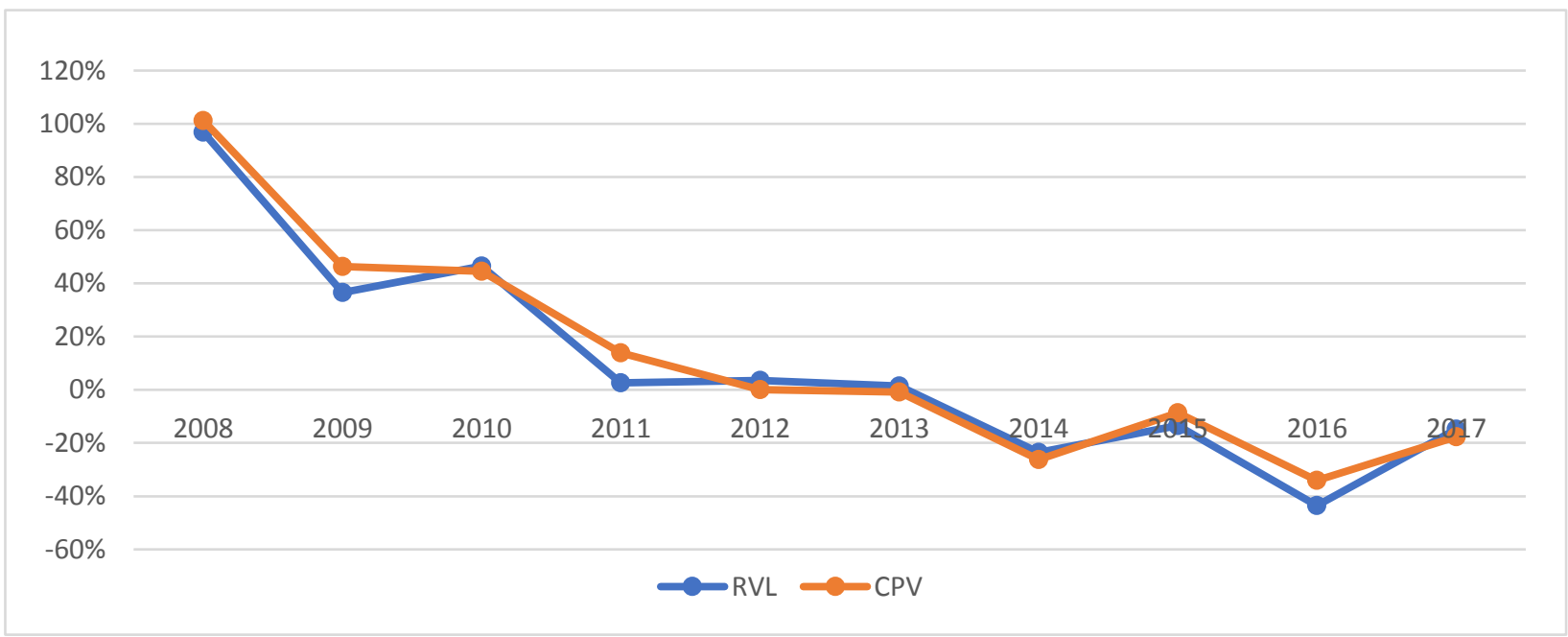

Figura 2. Média RL x Média CPV

Fonte: dados da pesquisa, 2018.

Analisando-se a Figura 2, percebe-se que a média das receitas segue 0 comportamento das variações individuais entre 2008 e 2010, apontando um aumento. Essa situação não se mantém entre 2011 e 2013, pois, apesar de a maior parte das 
empresas apresentar uma redução, a média indica um discreto aumento e volta a convergir com a variação individual, entre 2014 e 2017, com a redução da receita.

A média dos custos acompanha o desempenho individual da maior parte das empresas, pois os custos cresceram entre 2008 e 2012; no entanto, esse crescimento diminui de maneira gradativa, acentuando-se a partir de 2013, visto que o comportamento é declinante.

Conquanto não seja proporcional, torna-se visível que, a partir das médias apresentadas, os custos seguem a tendência da receita líquida no período analisado, o que significa dizer que, quando ela aumenta o CPV, também cresce. Se a receita diminui, os custos também diminuem. Este achado corrobora a teoria do sticky costs que tem a ideia central de que os custos variam assimetricamente as mudanças de receitas.

\subsection{Média dos custos e despesas em relação à RLV}

Complementando os resultados já apresentados, apresentam-se nesta seção as médias e os coeficientes de variação das seguintes relações: CPV/RL; DV/RL; DA/RL das 18 empresas investigadas no período de 2008 a 2017.

$\mathrm{Na}$ Tabela 3, apresentam-se as médias anuais e o coeficiente de variação da relação entre os custos dos produtos vendidos e a receita líquida. 
Comportamento dos Custos das Empresas de Construção Civil Listadas na B3 entre 2008 e 2017

Amanda Correia de Oliveira, Bárbara Vilela David, Valdemir da Silva, Kleber Luis Alves Guedes, José Jonas Alves Correia

Tabela 3

Relação CPV/RLV

\begin{tabular}{lcccccccccccc}
\hline \multicolumn{1}{c}{ Empresa } & $\mathbf{2 0 0 8}$ & $\mathbf{2 0 0 9}$ & $\mathbf{2 0 1 0}$ & $\mathbf{2 0 1 1}$ & $\mathbf{2 0 1 2}$ & $\mathbf{2 0 1 3}$ & $\mathbf{2 0 1 4}$ & $\mathbf{2 0 1 5}$ & $\mathbf{2 0 1 6}$ & $\mathbf{2 0 1 7}$ & Média & $\mathbf{C V}$ \\
\hline CONST A LIND & 0,53 & 0,47 & 0,44 & 0,60 & 0,51 & 0,53 & 0,53 & 0,51 & 0,61 & 0,84 & $\mathbf{0 , 5 6}$ & $\mathbf{0 , 2 0}$ \\
TENDA & 0,66 & 0,68 & 0,69 & 1,63 & 0,87 & 1,00 & 0,78 & 0,71 & 0,69 & 0,65 & $\mathbf{0 , 8 4}$ & $\mathbf{0 , 3 6}$ \\
CR2 & 0,72 & 0,78 & 0,75 & 0,61 & 0,79 & 0,72 & 0,53 & 0,68 & 0,72 & 0,72 & $\mathbf{0 , 7 0}$ & $\mathbf{0 , 1 1}$ \\
CYRELA REALT & 0,62 & 0,66 & 0,69 & 0,72 & 0,69 & 1,00 & 0,68 & 0,65 & 0,67 & 0,73 & $\mathbf{0 , 7 1}$ & $\mathbf{0 , 1 5}$ \\
DIRECIONAL & 0,59 & 0,66 & 0,68 & 0,72 & 0,73 & 0,77 & 0,77 & 0,79 & 0,88 & 0,95 & $\mathbf{0 , 7 6}$ & $\mathbf{0 , 1 4}$ \\
EVEN & 0,67 & 0,72 & 0,73 & 0,73 & 0,72 & 0,72 & 0,72 & 0,76 & 0,81 & 0,86 & $\mathbf{0 , 7 4}$ & $\mathbf{0 , 0 7}$ \\
AZTEC & 0,52 & 0,60 & 0,53 & 0,50 & 0,48 & 0,48 & 0,47 & 0,49 & 0,53 & 0,56 & $\mathbf{0 , 5 1}$ & $\mathbf{0 , 0 8}$ \\
GAFISA & 0,70 & 0,71 & 0,72 & 0,91 & 0,74 & 0,75 & 0,74 & 0,74 & 1,12 & 1,34 & $\mathbf{0 , 8 5}$ & $\mathbf{0 , 2 6}$ \\
HELBOR & 0,68 & 0,71 & 0,68 & 0,70 & 0,67 & 0,76 & 0,68 & 0,77 & 0,89 & 1,06 & $\mathbf{0 , 7 6}$ & $\mathbf{0 , 1 7}$ \\
JHSF PART & 0,52 & 0,67 & 0,60 & 0,57 & 0,51 & 0,53 & 0,51 & 0,57 & 0,60 & 0,59 & $\mathbf{0 , 5 7}$ & $\mathbf{0 , 0 9}$ \\
JOAO FORTES & 0,66 & 0,76 & 0,66 & 0,70 & 0,83 & 0,80 & 0,89 & 1,02 & 1,35 & 1,41 & $\mathbf{0 , 9 1}$ & $\mathbf{0 , 3 0}$ \\
MRV & 0,62 & 0,65 & 0,68 & 0,69 & 0,72 & 0,74 & 0,72 & 0,70 & 0,67 & 0,66 & $\mathbf{0 , 6 8}$ & $\mathbf{0 , 0 5}$ \\
PDG REALT & 0,65 & 0,71 & 0,71 & 0,74 & 1,19 & 0,79 & 0,81 & 1,02 & 3,94 & 0,94 & $\mathbf{1 , 1 5}$ & $\mathbf{0 , 8 6}$ \\
RNI & 0,64 & 0,74 & 0,69 & 0,78 & 0,69 & 0,68 & 0,71 & 0,71 & 0,90 & 0,96 & $\mathbf{0 , 7 5}$ & $\mathbf{0 , 1 4}$ \\
ROSSI RESID & 0,66 & 0,69 & 0,73 & 0,76 & 0,79 & 0,81 & 0,87 & 0,89 & 0,94 & 1,21 & $\mathbf{0 , 8 3}$ & $\mathbf{0 , 1 9}$ \\
TECNISA & 0,65 & 0,65 & 0,70 & 0,75 & 0,86 & 0,72 & 0,71 & 0,74 & 1,23 & 1,36 & $\mathbf{0 , 8 4}$ & $\mathbf{0 , 3 0}$ \\
TRISUL & 0,66 & 0,69 & 0,74 & 0,84 & 0,76 & 0,73 & 0,66 & 0,71 & 0,71 & 0,71 & $\mathbf{0 , 7 2}$ & $\mathbf{0 , 0 7}$ \\
VIVER & 0,77 & 0,76 & 0,71 & 0,86 & 1,60 & 1,10 & 1,48 & 1,50 & 3,25 & 2,50 & $\mathbf{1 , 4 5}$ & $\mathbf{0 , 5 8}$ \\
MÉDIA & $\mathbf{0 , 6 3}$ & $\mathbf{0 , 6 8}$ & $\mathbf{0 , 6 7}$ & $\mathbf{0 , 7 6}$ & $\mathbf{0 , 7 4}$ & $\mathbf{0 , 7 4}$ & $\mathbf{0 , 6 9}$ & $\mathbf{0 , 7 3}$ & $\mathbf{1 , 0 2}$ & $\mathbf{0 , 9 1}$ & $\mathbf{0 , 7 6}$ & $\mathbf{0 , 2 3}$ \\
CV & $\mathbf{0 , 1 0}$ & $\mathbf{0 , 1 0}$ & $\mathbf{0 , 1 2}$ & $\mathbf{0 , 3 1}$ & $\mathbf{0 , 3 3}$ & $\mathbf{0 , 2 1}$ & $\mathbf{0 , 3 0}$ & $\mathbf{0 , 3 0}$ & $\mathbf{0 , 8 1}$ & $\mathbf{0 , 4 6}$ & $\mathbf{0 , 2 7}$ & $\mathbf{0 , 9 0}$ \\
\hline
\end{tabular}

Nota. Fonte: dados da pesquisa, 2018.

Das empresas listadas no segmento de construção civil, na B3, observou-se que, em média, $76 \%$ da sua receita líquida de vendas são comprometidos com o custo dos produtos vendidos. Então a margem que resta é para garantir as despesas e gerar o lucro.

A empresa que apresenta a maior média é a Viver, com $145 \%$ da receita afetada pelo custo e um coeficiente de variação de $58 \%$. Para essa empresa, cabe destacar também que, em 6 dos 10 anos analisados, a receita líquida de vendas não foi suficiente para cobrir os custos dos produtos vendidos. A Pdg Realt também teve sua receita superada pelo custo, com uma média de 115\% e um coeficiente de variação de $86 \%$ durante o período investigado. Além disso, esta empresa, por três anos, 
apresentou o CPV maior que a RLV, tendo sido o pior desempenho evidenciado em 2015, prejudicando também a média do setor nesse ano.

Dentre as 18 entidades analisadas, a que obteve uma média menor na relação custos e receita líquida foi a Aztec, pois se verifica que seu custo comprometeu apenas $51 \%$ de sua RLV, e seu coeficiente de variação teve uma média de $8 \%$, ou seja, ela se manteve estável nos 10 anos de análise.

Outras 3 empresas que também obtiveram bons desempenhos durante os anos coletados: a Const. Land obteve uma média de 56\% e um CV de 20\%; a Jhsf Part revelou que cerca de $57 \%$ de sua RLV foi comprometida pelo custo e seu coeficiente de variação atingiu 9\%; e a MRV Engenharia alcançou 68\% do comprometimento da receita com uma taxa de variação de $5 \%$.

As outras 13 empresas possuem uma média entre $70 \%$ e $91 \%$ da receita líquida de vendas comprometida pelo custo e um coeficiente de variação que divergiu entre $7 \%$ e $36 \%$.

No que concerne à relação $D A / R L V$, a Tabela 4 revela que as despesas administrativas consomem, em média, 19\% da receita líquida da empresa. 
Comportamento dos Custos das Empresas de Construção Civil Listadas na B3 entre 2008 e 2017

Amanda Correia de Oliveira, Bárbara Vilela David, Valdemir da Silva, Kleber Luis Alves Guedes, José Jonas Alves Correia

Tabela 4

Relação DA/RLV

\begin{tabular}{lcccccccccccc}
\hline \multicolumn{1}{c}{ Empresa } & $\mathbf{2 0 0 8}$ & $\mathbf{2 0 0 9}$ & $\mathbf{2 0 1 0}$ & $\mathbf{2 0 1 1}$ & $\mathbf{2 0 1 2}$ & $\mathbf{2 0 1 3}$ & $\mathbf{2 0 1 4}$ & $\mathbf{2 0 1 5}$ & $\mathbf{2 0 1 6}$ & $\mathbf{2 0 1 7}$ & Média & $\mathbf{C V}$ \\
\hline CONST A LIND & 0,73 & 0,56 & 0,55 & 0,50 & 0,30 & 0,21 & 0,30 & 0,24 & 0,39 & 0,92 & $\mathbf{0 , 4 7}$ & $\mathbf{0 , 4 9}$ \\
TENDA & 0,26 & 0,11 & 0,07 & 0,20 & 0,10 & 0,12 & 0,15 & 0,10 & 0,09 & 0,07 & $\mathbf{0 , 1 3}$ & $\mathbf{0 , 4 8}$ \\
CR2 & 0,17 & 0,17 & 0,06 & 0,19 & 0,23 & 0,29 & 1,17 & 0,71 & 0,77 & 1,00 & $\mathbf{0 , 4 8}$ & $\mathbf{0 , 8 4}$ \\
CYRELA REALT & 0,15 & 0,11 & 0,07 & 0,07 & 0,07 & 0,07 & 0,08 & 0,09 & 0,14 & 0,15 & $\mathbf{0 , 1 0}$ & $\mathbf{0 , 3 4}$ \\
DIRECIONAL & 0,07 & 0,07 & 0,08 & 0,09 & 0,07 & 0,06 & 0,06 & 0,07 & 0,08 & 0,14 & $\mathbf{0 , 0 8}$ & $\mathbf{0 , 3 0}$ \\
EVEN & 0,18 & 0,12 & 0,05 & 0,07 & 0,07 & 0,07 & 0,09 & 0,08 & 0,08 & 0,10 & $\mathbf{0 , 0 9}$ & $\mathbf{0 , 3 9}$ \\
AZTEC & 0,19 & 0,11 & 0,13 & 0,13 & 0,15 & 0,07 & 0,11 & 0,12 & 0,15 & 0,09 & $\mathbf{0 , 1 2}$ & $\mathbf{0 , 2 7}$ \\
GAFISA & 0,10 & 0,08 & 0,07 & 0,09 & 0,09 & 0,09 & 0,08 & 0,07 & 0,12 & 0,15 & $\mathbf{0 , 0 9}$ & $\mathbf{0 , 2 7}$ \\
HELBOR & 0,06 & 0,03 & 0,04 & 0,04 & 0,05 & 0,04 & 0,06 & 0,07 & 0,10 & 0,17 & $\mathbf{0 , 0 7}$ & $\mathbf{0 , 6 5}$ \\
JHSF PART & 0,10 & 0,12 & 0,07 & 0,07 & 0,08 & 0,11 & 0,12 & 0,13 & 0,24 & 0,29 & $\mathbf{0 , 1 3}$ & $\mathbf{0 , 5 6}$ \\
JOAO FORTES & 0,34 & 0,13 & 0,10 & 0,11 & 0,14 & 0,09 & 0,12 & 0,13 & 0,26 & 0,29 & $\mathbf{0 , 1 7}$ & $\mathbf{0 , 5 2}$ \\
MRV & 0,08 & 0,06 & 0,05 & 0,05 & 0,05 & 0,06 & 0,06 & 0,06 & 0,07 & 0,07 & $\mathbf{0 , 0 6}$ & $\mathbf{0 , 1 4}$ \\
PDG REALT & 0,08 & 0,06 & 0,07 & 0,07 & 0,10 & 0,08 & 0,09 & 0,14 & 0,82 & 0,29 & $\mathbf{0 , 1 8}$ & $\mathbf{1 , 3 2}$ \\
RNI & 0,10 & 0,11 & 0,11 & 0,11 & 0,12 & 0,12 & 0,13 & 0,14 & 0,18 & 0,22 & $\mathbf{0 , 1 3}$ & $\mathbf{0 , 2 9}$ \\
ROSSI RESID & 0,09 & 0,08 & 0,08 & 0,09 & 0,08 & 0,09 & 0,11 & 0,13 & 0,21 & 0,25 & $\mathbf{0 , 1 2}$ & $\mathbf{0 , 4 8}$ \\
TECNISA & 0,15 & 0,11 & 0,07 & 0,08 & 0,13 & 0,10 & 0,11 & 0,13 & 0,33 & 0,25 & $\mathbf{0 , 1 5}$ & $\mathbf{0 , 5 6}$ \\
TRISUL & 0,15 & 0,09 & 0,06 & 0,07 & 0,09 & 0,08 & 0,15 & 0,12 & 0,14 & 0,09 & $\mathbf{0 , 1 0}$ & $\mathbf{0 , 3 0}$ \\
VIVER & 0,15 & $\mathbf{0 , 1 4}$ & $\mathbf{0 , 0 9}$ & 0,09 & 0,23 & 0,10 & 0,25 & 0,28 & 1,26 & 5,19 & $\mathbf{0 , 7 8}$ & $\mathbf{2 , 0 4}$ \\
Média & $\mathbf{0 , 1 7}$ & $\mathbf{0 , 1 3}$ & $\mathbf{0 , 1 0}$ & $\mathbf{0 , 1 2}$ & $\mathbf{0 , 1 2}$ & $\mathbf{0 , 1 0}$ & $\mathbf{0 , 1 8}$ & $\mathbf{0 , 1 6}$ & $\mathbf{0 , 3 0}$ & $\mathbf{0 , 5 4}$ & $\mathbf{0 , 1 9}$ & $\mathbf{0 , 5 7}$ \\
CV & $\mathbf{0 , 9 0}$ & $\mathbf{0 , 9 1}$ & $\mathbf{1 , 1 2}$ & $\mathbf{0 , 8 8}$ & $\mathbf{0 , 5 8}$ & $\mathbf{0 , 5 7}$ & $\mathbf{1 , 4 2}$ & $\mathbf{0 , 9 6}$ & $\mathbf{1 , 0 8}$ & $\mathbf{2 , 2 0}$ & $\mathbf{0 , 9 8}$ & $\mathbf{0 , 8 0}$ \\
\hline
\end{tabular}

Nota. Fonte: dados da pesquisa, 2018.

Com relação às despesas administrativas, mais uma vez a Construtora Viver foi a que teve a sua receita líquida mais comprometida com uma média de $78 \%$. Esse resultado foi influenciado majoritariamente pelo ano de 2017, pois este apresentou maior comprometimento das receitas de vendas com as despesas administrativas, 0 que também resultou em um alto coeficiente de variação (204\%). Em seguida, destacam-se as empresas Cr2 e Const. Land, com uma média de, respectivamente, $48 \%$ e 47\%; já o coeficiente de variação dessas empresas foi de $84 \%$ e $49 \%$, nesta ordem.

As empresas que apresentaram o menor comprometimento da receita com despesas administrativas foram a MRV Engenharia, com uma média de 6\%, seguida, 
Comportamento dos Custos das Empresas de Construção Civil Listadas na B3 entre 2008 e 2017

Amanda Correia de Oliveira, Bárbara Vilela David, Valdemir da Silva, Kleber Luis Alves Guedes, José Jonas Alves Correia

respectivamente, por Helbort - 7\%, Direcional - 8\%, Even - 9\%, Gafisa - 9\%, Cyrela $10 \%$ e Trisul - 10\%. As outras variaram entre $12 \%$ e $18 \%$.

A respeito da receita comprometida pelas despesas de vendas, a Tabela 5 evidencia que a média geral dos 10 anos analisados é de $8 \%$. Vale ressaltar que a empresa Const, A Lind apresenta, em sua Demonstração do Resultado, despesas com vendas apenas em 2010 e 2011, com influência nula na média geral.

Tabela 5

Relação DV/RLV

\begin{tabular}{lcccccccccccc}
\hline \multicolumn{1}{c}{ Empresa } & $\mathbf{2 0 0 8}$ & $\mathbf{2 0 0 9}$ & $\mathbf{2 0 1 0}$ & $\mathbf{2 0 1 1}$ & $\mathbf{2 0 1 2}$ & $\mathbf{2 0 1 3}$ & $\mathbf{2 0 1 4}$ & $\mathbf{2 0 1 5}$ & $\mathbf{2 0 1 6}$ & $\mathbf{2 0 1 7}$ & Média & CV \\
\hline CONST A LIND & 0,00 & 0,00 & 0,01 & 0,01 & 0,00 & 0,00 & 0,00 & 0,00 & 0,00 & 0,00 & $\mathbf{0 , 0 0}$ & $\mathbf{2 , 2 0}$ \\
TENDA & 0,18 & 0,12 & 0,10 & 0,41 & 0,08 & 0,09 & 0,09 & 0,08 & 0,09 & 0,10 & $\mathbf{0 , 1 3}$ & $\mathbf{0 , 7 5}$ \\
CR2 & 0,12 & 0,06 & 0,04 & 0,05 & 0,14 & 0,05 & 0,20 & 0,13 & 0,14 & 0,08 & $\mathbf{0 , 1 0}$ & $\mathbf{0 , 5 3}$ \\
CYRELA REALT & 0,13 & 0,07 & 0,08 & 0,08 & 0,08 & 0,08 & 0,08 & 0,11 & 0,13 & 0,13 & $\mathbf{0 , 1 0}$ & $\mathbf{0 , 2 4}$ \\
DIRECIONAL & 0,06 & 0,04 & 0,03 & 0,03 & 0,03 & 0,02 & 0,03 & 0,03 & 0,04 & 0,08 & $\mathbf{0 , 0 4}$ & $\mathbf{0 , 5 1}$ \\
EVEN & 0,11 & 0,06 & 0,04 & 0,05 & 0,05 & 0,07 & 0,08 & 0,08 & 0,09 & 0,09 & $\mathbf{0 , 0 7}$ & $\mathbf{0 , 2 8}$ \\
AZTEC & 0,08 & 0,03 & 0,04 & 0,04 & 0,06 & 0,04 & 0,06 & 0,06 & 0,10 & 0,07 & $\mathbf{0 , 0 6}$ & $\mathbf{0 , 3 5}$ \\
GAFISA & 0,09 & 0,07 & 0,08 & 0,13 & 0,08 & 0,09 & 0,06 & 0,07 & 0,10 & 0,14 & $\mathbf{0 , 0 9}$ & $\mathbf{0 , 3 0}$ \\
HELBOR & 0,08 & 0,08 & 0,07 & 0,06 & 0,06 & 0,07 & 0,08 & 0,06 & 0,06 & 0,15 & $\mathbf{0 , 0 8}$ & $\mathbf{0 , 3 6}$ \\
JHSF PART & 0,05 & 0,12 & 0,07 & 0,07 & 0,05 & 0,11 & 0,05 & 0,04 & 0,05 & 0,03 & $\mathbf{0 , 0 6}$ & $\mathbf{0 , 4 6}$ \\
JOAO FORTES & 0,03 & 0,05 & 0,05 & 0,08 & 0,10 & 0,07 & 0,07 & 0,09 & 0,17 & 0,24 & $\mathbf{0 , 0 9}$ & $\mathbf{0 , 6 7}$ \\
MRV & 0,08 & 0,06 & 0,05 & 0,06 & 0,07 & 0,07 & 0,09 & 0,10 & 0,12 & 0,12 & $\mathbf{0 , 0 8}$ & $\mathbf{0 , 2 9}$ \\
PDG REALT & 0,09 & 0,06 & 0,06 & 0,06 & 0,06 & 0,04 & 0,05 & 0,09 & 0,58 & 0,07 & $\mathbf{0 , 1 1}$ & $\mathbf{1 , 4 3}$ \\
RNI & 0,10 & 0,08 & 0,07 & 0,05 & 0,04 & 0,06 & 0,05 & 0,09 & 0,14 & 0,13 & $\mathbf{0 , 0 8}$ & $\mathbf{0 , 4 2}$ \\
ROSSI RESID & 0,11 & 0,07 & 0,10 & 0,09 & 0,11 & 0,07 & 0,11 & 0,09 & 0,14 & 0,12 & $\mathbf{0 , 1 0}$ & $\mathbf{0 , 2 0}$ \\
TECNISA & 0,12 & 0,07 & 0,05 & 0,06 & 0,07 & 0,05 & 0,04 & 0,04 & 0,10 & 0,11 & $\mathbf{0 , 0 7}$ & $\mathbf{0 , 4 4}$ \\
TRISUL & 0,14 & 0,07 & 0,06 & 0,05 & 0,05 & 0,08 & 0,08 & 0,08 & 0,13 & 0,09 & $\mathbf{0 , 0 8}$ & $\mathbf{0 , 3 7}$ \\
VIVER & 0,15 & 0,10 & 0,07 & 0,09 & 0,12 & 0,03 & 0,08 & 0,11 & 0,28 & 0,50 & $\mathbf{0 , 1 5}$ & $\mathbf{0 , 9 0}$ \\
Média & $\mathbf{0 , 1 0}$ & $\mathbf{0 , 0 7}$ & $\mathbf{0 , 0 6}$ & $\mathbf{0 , 0 8}$ & $\mathbf{0 , 0 7}$ & $\mathbf{0 , 0 6}$ & $\mathbf{0 , 0 7}$ & $\mathbf{0 , 0 7}$ & $\mathbf{0 , 1 4}$ & $\mathbf{0 , 1 2}$ & $\mathbf{0 , 0 8}$ & $\mathbf{0 , 5 9}$ \\
CV & $\mathbf{0 , 4 5}$ & $\mathbf{0 , 4 3}$ & $\mathbf{0 , 4 0}$ & $\mathbf{1 , 0 6}$ & $\mathbf{0 , 5 0}$ & $\mathbf{0 , 4 4}$ & $\mathbf{0 , 5 7}$ & $\mathbf{0 , 4 3}$ & $\mathbf{0 , 9 3}$ & $\mathbf{0 , 8 5}$ & $\mathbf{0 , 4 1}$ & $\mathbf{0 , 8 4}$ \\
\hline
\end{tabular}

Nota. Fonte: dados da pesquisa, 2018.

Nota-se que as empresas se mantiveram com médias próximas ao longo do período em análise. Desconsiderando a empresa Const a Lind, a empresa com a qual houve maior implicação foi a Tenda, com 13\%; a que obteve menor média de DV foi a 
Direcional, com um comprometimento de $4 \%$ da receita líquida. As outras variaram entre $6 \%$ e $10 \%$.

Assim, para a apresentação das médias que custos, despesas administrativas e despesas de vendas consomem da receita líquida de venda, é utilizado a Figura 3 que, além das médias anuais, indica a média geral dos 10 anos de análise.

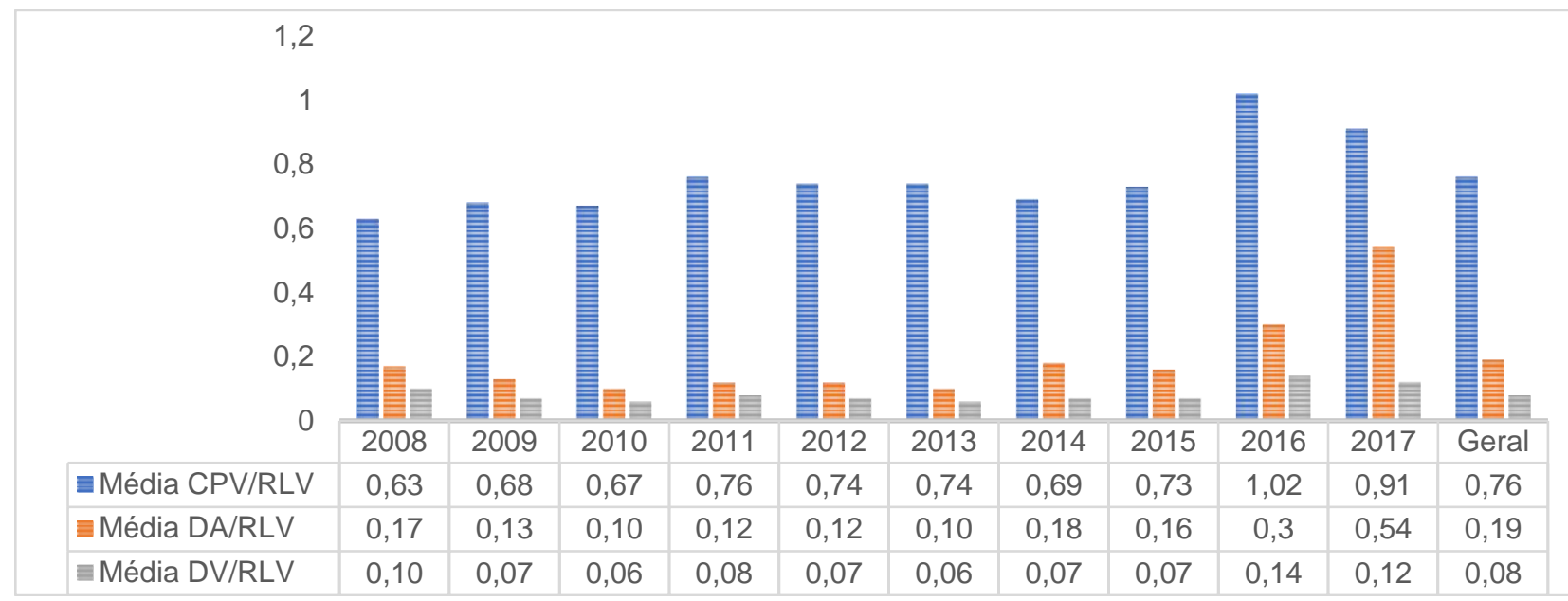

Figura 3. Média dos custos e despesas em relação a RLV

Fonte: dados da pesquisa, 2018.

Por meio da Figura 3, torna-se mais claro que, de forma geral, a maior parte da RLV é comprometida pelo CPV (76\%), seguido das despesas administrativas (19\%) e, por último, as despesas com vendas (8\%).

Tais resultados convergem com o encontrado por Silva, Leal e Trindade (2015), que obtiveram uma média de $76 \%$ da RLV destinada a cobrir o CPV no segmento de carnes e derivados, 12,7\% para as despesas de vendas e 3,6\% para as despesas administrativas, sendo esse último divergente em relação ao encontrado neste estudo, já que a DA é a segunda que mais consome RLV.

Semelhantemente aos resultados do segmento de construção civil, Richartz e Borgert (2014) avaliaram empresas dos diversos setores da economia: encontraram a 
Comportamento dos Custos das Empresas de Construção Civil Listadas na B3 entre 2008 e 2017

Amanda Correia de Oliveira, Bárbara Vilela David, Valdemir da Silva, Kleber Luis Alves Guedes, José

Jonas Alves Correia

média de $71,25 \%$ da RLV comprometidas com os custos e $10 \%$ tanto para as despesas administrativas quanto para as de vendas.

\section{CONSIDERAÇÕES FINAIS}

Compreender o comportamento dos custos é essencial para o gerenciamento de uma organização, já que servem para a tomada de decisão, bem como para projeções futuras. Além disso, em um mundo cada vez mais globalizado, gerenciar os custos contribui para tornar uma empresa mais competitiva e lucrativa. No que se refere às empresas do ramo de construção civil, esse processo é ainda mais importante, já que se trata de projetos de média duração, para os quais os custos projetados precisam ser bem elaborados e controlados durante a execução das obras, para que a empresa atinja seu objetivo: o lucro. Assim, o objetivo geral deste estudo foi identificar o comportamento dos custos das empresas do segmento de construção civil, listadas na B3 entre 2008 e 2017.

Nesta pesquisa, os resultados indicaram que os custos e despesas acompanham as variações das receitas de forma assimétrica, enquadrando-se na premissa da teoria do Sticky Costs. Este resultado reflete, na maioria das empresas, a preocupação em equilibrar os gastos com os ganhos. Os custos dos produtos vendidos são os que mais comprometem a receita, cerca de $76 \%$, enquanto as despesas administrativas consomem 19\%, e as de vendas, apenas $8 \%$. Essa é a tendência identificada em estudos anteriores, com empresas listadas na bolsa de valores B3 de diferentes atividades.

Este estudo também evidencia a forte relação entre 0 desenvolvimento econômico do país e os bons resultados do segmento da construção civil. Isto é perceptível quando comparado às variações positivas da receita líquida de 2008 a 2010 (período que recebeu influência dos programas sociais de 2007 e 2009 do governo federal) com os anos de 2014 a 2016 (crise econômica), que demonstra variações negativas da receita, refletindo também em 2017. 
Comportamento dos Custos das Empresas de Construção Civil Listadas na B3 entre 2008 e 2017

Amanda Correia de Oliveira, Bárbara Vilela David, Valdemir da Silva, Kleber Luis Alves Guedes, José

Jonas Alves Correia

Dessa forma, o estudo se mostra relevante, porque, ao analisar empresas com ações no mercado de capitais, os resultados encontrados podem servir de parâmetro para avaliações dos investidores, sobretudo no que diz respeito ao desempenho econômico.

Ressalta-se que, devido à limitação deste estudo para um segmento, os resultados obtidos não podem ser generalizados, sendo válidos apenas para as empresas listadas no segmento da construção civil, na B3.

Assim sendo, sugere-se que outros estudos sobre o comportamento dos custos sejam aplicados em outras empresas, listadas ou não na B3, buscando-se descobrir se os fatores determinantes, as decisões governamentais, o efeito tecnológico contribuem para o comportamento dos custos, por estado ou por região, bem como o aprofundamento na teoria sticky costs, visando disseminar, dessa forma, o debate científico e o conhecimento contábil, além de contribuir para o crescimento das empresas, fazendo com que estas se mantenham no mercado, gerando empregos e proporcionando o crescimento econômico.

\section{REFERÊNCIAS}

Beüren, I. M. (2008). Como elaborar trabalhos monográficos em contabilidade: teoria e prática. (2a ed.). São Paulo: Atlas.

B3. Empresas listadas. (2018). Recuperado de: <http://www.bmfbovespa.com.br/ptbr/pr odutos/listados-a-vista-e-derivativos/renda-variavel/empresas-listadas.htm $>$. Acesso em: 20/maio/2018.

Bornia, A. C. (2002). Análise gerencial de custos: aplicação em empresas modernas. Porto Alegre: Bookman.

Brasil. (2018). Decreto $n^{\circ}$ 6.025, de 22 de janeiro de 2007. Recuperado de: <http://www.planalto.gov.br/ccivil_03/_ato20072010/2007/decreto/d6025.htm>. Acesso em: 02/jul./2018. 
Comportamento dos Custos das Empresas de Construção Civil Listadas na B3 entre 2008 e 2017

Amanda Correia de Oliveira, Bárbara Vilela David, Valdemir da Silva, Kleber Luis Alves Guedes, José

Jonas Alves Correia

Brasil. (2018). Decreto-lei no 11.977, de 07 de julho de 2009. Recuperado de: http://www.planalto.gov.br/ccivil_03/_ato2007-2010/2009/lei//11977.htm. Acesso em: 09/jun./2018.

Cabral, J. G. D. (2015). A importância de gestão de custos em empresa de construção civil.

Recuperado

de:

<http://www.techoje.com.br/site/techoje/categoria/detalhe_artigo/2200>. Acesso em: 08 jun. 2018.

Câmara Brasileira da Indústria da Construção - CBIC (2018). PIB Brasil e Construção Civil. Recuperado de: <http://www.cbicdados.com.br/menu/pib-e-investimento/pibbrasil-e-construcao-civil>. Acesso em: 05/jun./2018.

Duarte, M. P. L. (Julho, 2013). O governo Vargas e as primeiras tentativas do estado na provisão de habitação popular. Simpósio Nacional de História. Natal, RN, Brasil, 27.

Engelage, E., Vargas, L. A., Reis, L. S., \& Borgert, A. (2017). Comportamento de custos das empresas brasileiras listadas na BM\&FBOVESPA em períodos de instabilidade econômica. Congresso Brasileiro de Custos - ABC. Florianópolis, SC, Brasil, 24.

Fazoli, J. C., Reis, L S., \& Borgert, A. (2018). O comportamento dos custos das indústrias do estado de Santa Catarina com ênfase nos Sticky costs. Enfoque, v. 37, n. 2, p. 37, 2018.

Ferrari, M. J., Kremer, A. W., \& Pinheiro, N. S. (2013). Análise do comportamento dos custos no setor de telecomunicações. Congresso Brasileiro de Custos - ABC. Uberlândia, MG, Brasil, 20.

Fontenele Filho, J. O., \& Correia Neto, J. F. (2014). Análise da importância de ferramentas para a gestão de custos no ambiente da construção civil. Congresso Brasileiro de Custos - ABC. Natal, RN, Brasil, 21.

Gomes, I. S., De Lima, D. H. S., \& Steppan, A. I. B. (2007). Análise do comportamento dos custos hospitalares indiretos: uma investigação empírica do custo hospitalar de energia elétrica no setor de radioterapia da liga norte-rio-grandense contra o câncer. Congresso Brasileiro de Custos - $A B C$. João Pessoa, PE, Brasil, 14.

Lima, G. A. S. F. D., Egito, M. O. T. D., \& Silva, J. D. G. D. (2004). Utilização de Informações de Custos no Processo Gerencial: estudo comparativo entre a hotelaria do estado do Rio Grande do Norte e a região nordeste, sob a ótica da gestão econômico-financeira. Revista Contabilidade \& Finanças, 15(SPE), 106-116.

Macedo, M. A. S., Sancovschi, M., de Souza Leira, S. O., \& da Silva, R. C. (2016). Comportamento dos custos das operadoras de saúde reguladas pela ANS entre 
Comportamento dos Custos das Empresas de Construção Civil Listadas na B3 entre 2008 e 2017

Amanda Correia de Oliveira, Bárbara Vilela David, Valdemir da Silva, Kleber Luis Alves Guedes, José

Jonas Alves Correia

2001 a 2015: uma análise com base em Sticky Costs. Congresso Brasileiro de Custos - $A B C$. Porto de Galinhas, PE, Brasil, 23.

Maher, M. (2001). Contabilidade de custos: criando valor para a administração. São Paulo: Atlas.

Martins, E. (2009). Contabilidade de custos. (9a ed.). São Paulo: Atlas.

Martins, J. C. (2018). Os impactos da crise econômica na indústria da construção civil. 2016. Recuperado de: <https://www.youtube.com/watch?v=fzJ7kx8lpiU>. Acesso em: 06/maio/2018.

Medeiros, O. R. D., Costa, P. D. S., \& Silva, C. A. T. (2005). Testes empíricos sobre o comportamento assimétrico dos custos nas empresas brasileiras. Revista Contabilidade \& Finanças, 16(38), 47-56.

Oliveira, D. F. (2012). Evolução e financiamento do setor da construção civil residencial no Brasil. (Trabalho de Conclusão Bacharel em Ciências Econômicas). Instituto de Economia, Universidade Estadual de Campinas - UNICAMP, São Paulo, SP, Brasil.

Richartz, F., Borgert, A., Vicente, E. F. R., \& Ferrari, M. J. (2012). Comportamento dos custos das empresas brasileiras listadas no segmento de Fios e Tecidos da BM\&FBOVESPA entre 1998 e 2010. Congresso Brasileiro de Custos - ABC. Bento Gonçalves, RS, Brasil, 19.

Richardson, R. J. (2017). Pesquisa social: métodos e técnicas. (4a ed.). São Paulo: Saraiva.

Richartz, F., \& Borgert, A. (2014). O comportamento dos custos das empresas brasileiras listadas na BM\&FBOVESPA entre 1994 e 2011, com ênfase nos sticky costs. Contaduría y administración, 59(4), 39-70.

Rigo, V. P., de Godoy, N., \& Scarpin, J. E. (2015). Comportamento dos custos nas empresas do segmento de alimentos listadas na BM\&FBovespa. ABCustos, 10(2).

Shank, J. K., \& Govindarajan, V. (1997). A revolução dos custos: como reinventar e redefinir sua estratégia de custos para vencer em mercados crescentemente competitivos. Elsevier.

Silva, I. F. U., Leal, E. A. L. A., \& Trindade, J. A. S. (2015). Comportamento dos custos nas empresas listadas na BM\&F Bovespa do segmento de carnes e derivados nos anos de 2004 a 2013. ABCustos, 10(1). 
Comportamento dos Custos das Empresas de Construção Civil Listadas na B3 entre 2008 e 2017

Amanda Correia de Oliveira, Bárbara Vilela David, Valdemir da Silva, Kleber Luis Alves Guedes, José Jonas Alves Correia

Sindicato Nacional da Indústria da Construção Pesada - SINICON. (2017). Das 3 atividades mais afetadas pela crise, só construção segue em queda. Recuperado de: $\quad<$ https://www.sinicon.org.br/files/2017.09.01Das-3-atividades-mais-afetadaspela-cris -so-construcao-segue-em-queda.pdf>. Acesso em: 06/maio/2018.

Sindicato Nacional da Indústria da Construção Pesada - SINICON. (2018). Evolução do emprego da construção pesada. Recuperado de: $<$ https://www.sinicon.org.br/wa_files/emprego\%20na\%20construcao\%20brasil\%20m ai\%20-\%202018.pdf>. Acesso em: 06/maio/2018.

Souza, B. A., Oliveira, C. A. C., Santana, J. C. O. D., Viana Neto, L. A. D. C., \& Santos, D. D. G. (2015). Análise dos indicadores PIB nacional e PIB da indústria da construção civil. RDE-Revista de Desenvolvimento Econômico, 17(31).

Data de Submissão: 16/01/2019

Data de Aceite: 05/08/2019 